\title{
DIRECTIONAL CORRELATIONS OF GAMMA RAYS IN ${ }^{\mathbf{7 7}}$ As $^{\dagger}$
}

\author{
R. N. CHERRY, Jr. ${ }^{\dagger \dagger}$ and M. L. WIEDENBECK \\ Department of Physics, The University of Michigan, Ann Arbor, Michigan USA 48104
}

Received 17 June 1975

(Revised 21 July 1975)

\begin{abstract}
Directional correlation measurements have been made for $\gamma$-transitions in ${ }^{77}$ As following the decay of $11.30 \mathrm{~h}{ }^{77} \mathrm{Ge}$ using two $\mathrm{Ge}(\mathrm{Li})$ detectors. Using the method of Chow et al., mixing ratios of $\gamma$-transitions and the spins of seven levels have been deduced assuming only

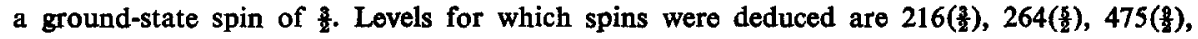
632( $\left(\frac{5}{2}\right), 1189\left(\frac{7}{2}\right), 1458\left(\frac{3}{2}\right)$ and $1528\left(\frac{5}{2}\right) \mathrm{keV}$.
\end{abstract}

RADIOACTIVITY ${ }^{77} \mathrm{Ge}$ [from ${ }^{76} \mathrm{Ge}(\mathrm{n}, \gamma)$ ]; measured $\gamma \gamma(\theta) .{ }^{77}$ As levels deduced $J$, $\gamma$ mixing ratios.

\section{Introduction}

Previous investigators ${ }^{1-4}$ ) of directional correlations of $\gamma$-rays in ${ }^{77}$ As following the decay of $11.30 \mathrm{~h}{ }^{77} \mathrm{Ge}$ have used at least one $\mathrm{NaI}(\mathrm{Tl})$ detector in their experiments. In addition, no results for triple cascades in ${ }^{77}$ As have been reported. The present work employs two $\mathrm{Ge}(\mathrm{Li})$ detectors and uses their improved resolution to obtain results for nineteen correlations, twelve of which have not been previously reported. Results for directional correlations of ten triple cascades have also been obtained. Using these results in the method of Chow, Gardulski, and Wiedenbeck ${ }^{5}$ ) and assuming only that the spin of the ground state of ${ }^{77} \mathrm{As}$ is $\frac{3}{2}$, the mixing ratios of the 367 and $416 \mathrm{keV}$ transitions and the spins of the 216,264 and $632 \mathrm{keV}$ levels were deduced. It was then possible to deduce the spins of the 475, 1189, 1458 and $1528 \mathrm{keV}$ levels and mixing ratios for several other $\gamma$-transitions.

\section{Experimental procedures}

Samples of $\mathrm{GeO}_{2}$ enriched to $74 \%$ in ${ }^{76} \mathrm{Ge}$ were irradiated in the thermal neutron flux $\left(\approx 3 \times 10^{13} \mathrm{n} / \mathrm{cm}^{2} \cdot \mathrm{sec}\right)$ of the University of Michigan Ford Nuclear Reactor for periods of approximately $36 \mathrm{~h}$. The samples were set aside for about eight hours to allow the $82 \mathrm{~min}{ }^{75} \mathrm{Ge}$ to decay away and then dissolved in hydroflouric acid and placed in lucite holders.

The directional correlation studies utilized 29 and $32 \mathrm{~cm}^{3} \mathrm{Ge}(\mathrm{Li})$ detectors. The

t Work supported in part by the National Science Foundation.

t† Present address: Department of Physics, Hamilton College, Clinton, New York, USA 13323. 
$29 \mathrm{~cm}^{3}$ detector was held fixed and the $32 \mathrm{~cm}^{3}$ detector was moved from $90^{\circ}$ to $270^{\circ}$, stopping at $15^{\circ}$ intervals for $90 \mathrm{~min}$. The spectra were recorded in a Nuclear Data 50/50 multichannel analyzer operating in the two-parameter mode. Digital gates were set for both the peak of interest and an adjacent Compton region.

Corrections were made to the data at each angle for chance coincidences, source decay and contributions due to Compton scattering. The data resulting from the seven angles in the first quadrant were then added to those from the second quadrant, and a least squares fit to the correlation function was performed following the method of Rose ${ }^{6}$ ). Geometric corrections to the correlation coefficients due to the finite angle subtended at the source by the detectors were obtained using the method of Camp and Van Lehn ${ }^{7}$ ).

\section{Analysis and results}

The results of the $\gamma-\gamma$ directional correlation measurements are given in table 1 . A partial level scheme ${ }^{8}$ ) is presented in fig. 1 . Only transitions and levels studied in the present investigation are shown. A $\gamma$-spectrum taken with the $29 \mathrm{~cm}^{3}$ detector is presented in fig. 2. Graphs of the normalized data and the correlation function

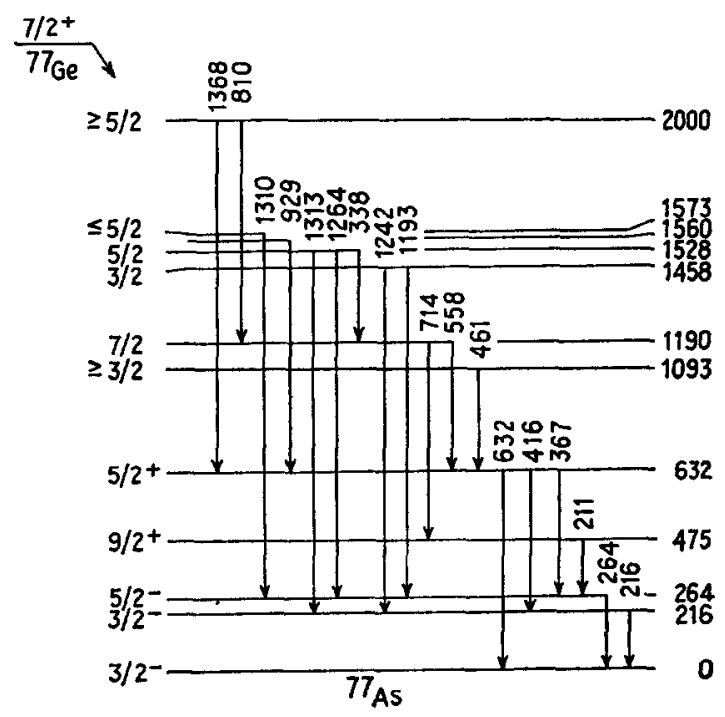

Fig. 1. Partial level scheme of ${ }^{77}$ As [ref. ${ }^{8}$ )] with spins deduced in the present study.

$W(\theta)$ before making geometrical corrections are presented for the (367-264) $\mathrm{keV}$ correlation and the (558-264) keV first-third correlation in figs. 3 and 4, respectively. The sign convention of Krane and Steffen ${ }^{9}$ ) for the mixing ratio $\delta$ of the $\gamma$-transitions is used throughout. 


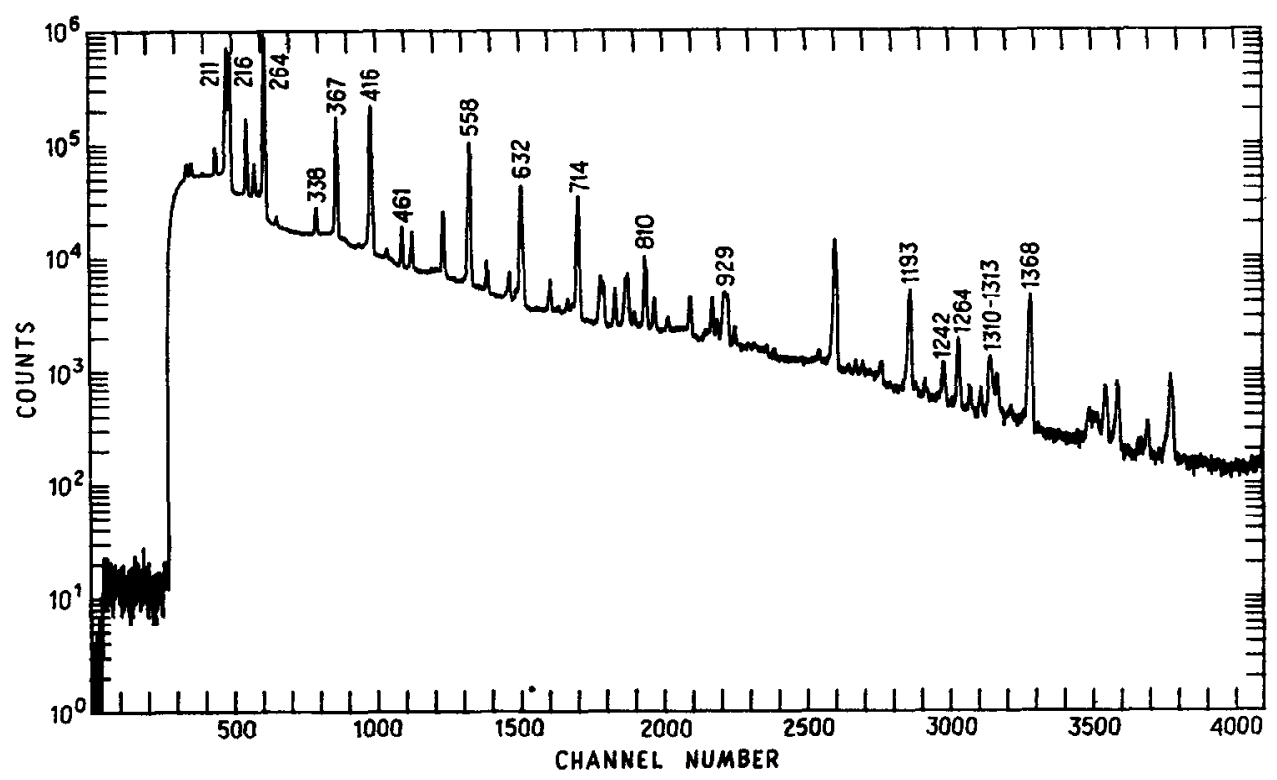

Fig. 2. Gamma-ray spectrum following the decay of $11.30^{77} \mathrm{Ge}$ to levels in ${ }^{77}$ As. Only transitions used in the correlations are labeled.

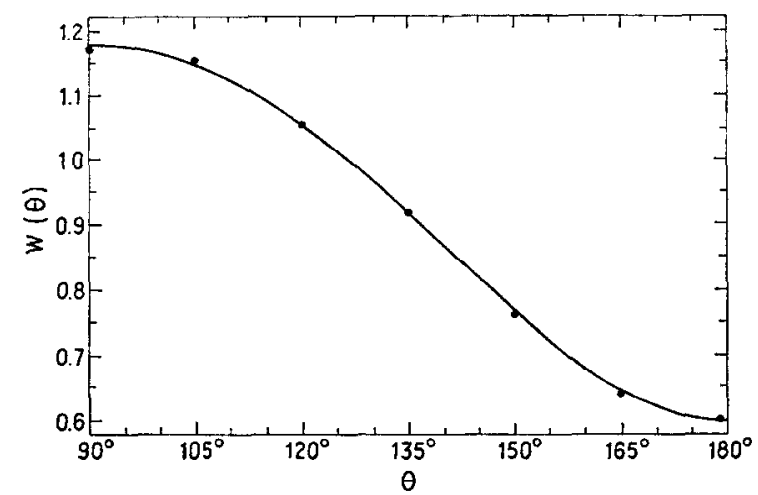

Fig. 3. Normalized data values and the correlation function $W(\theta)$ (before geometric corrections) versus the angle $\theta$ between the detectors for the $(367-264) \mathrm{keV}$ correlation. Errors of the data values are less than $0.3 \%$.

\subsection{ANALYSIS OF THE TRIPLE CASCADES}

It has been shown by Chow, Gardulski and Wiedenbeck ${ }^{5}$ ) that if correlation coefficients are obtained for the first-second, second-third and first-third correlations in a triple cascade, then the mixing ratio of the second transition depends only on the spins of the intermediate levels and is a solution of a polynomial of fourth order in $\delta$. This method was used to determine the mixing ratios of the 367 and 


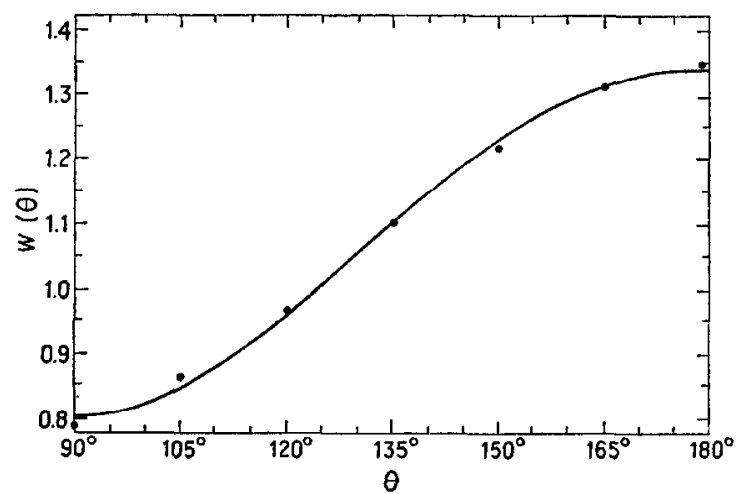

Fig. 4. Normalized data values and the correlation function $W(\theta)$ (before geometric corrections) versus the angle $\theta$ between the detectors for the $(558-264) \mathrm{keV}$ correlation. Errors of the data values are less than $0.4 \%$.

TABLE 1

The $\gamma-\gamma$ directional correlation coefficients in ${ }^{77} \mathrm{As}$

\begin{tabular}{rrr}
\hline Cascade $[E(\mathrm{keV})]$ & \multicolumn{1}{c}{$A_{22}$} & \multicolumn{1}{c}{$A_{\mathbf{4}}$} \\
\hline $211-264$ & $-0.175 \pm 0.003$ & $-0.028 \pm 0.004$ \\
$416-216$ & $0.005 \pm 0.003$ & $-0.003 \pm 0.004$ \\
$462-216$ & $-0.005 \pm 0.026$ & $-0.020 \pm 0.035$ \\
$558-216$ & $-0.014 \pm 0.004$ & $-0.039 \pm 0.006$ \\
$929-216$ & $0.050 \pm 0.033$ & $-0.095 \pm 0.044$ \\
$1242-216$ & $0.170 \pm 0.065$ & $0.139 \pm 0.088$ \\
$1313-216$ & $0.101 \pm 0.038$ & $0.043 \pm 0.052$ \\
$1368-216$ & $0.030 \pm 0.024$ & $-0.025 \pm 0.032$ \\
$367-264$ & $-0.393 \pm 0.003$ & $-0.032 \pm 0.004$ \\
$558-264$ & $0.388 \pm 0.012$ & $-0.034 \pm 0.016$ \\
$1193-264$ & $0.643 \pm 0.004$ & $0.051 \pm 0.006$ \\
$1264-264$ & $-0.494 \pm 0.045$ & $0.103 \pm 0.059$ \\
$1310-264$ & $-0.471 \pm 0.042$ & $0.050 \pm 0.056$ \\
$1368-264$ & $0.119 \pm 0.018$ & $0.001 \pm 0.025$ \\
$338-416$ & $0.061 \pm 0.014$ & $-0.089 \pm 0.018$ \\
$338-558$ & $0.089 \pm 0.026$ & $-0.001 \pm 0.035$ \\
$558-367$ & $-0.108 \pm 0.007$ & $-0.019 \pm 0.009$ \\
$810-367$ & $-0.043 \pm 0.031$ & $0.008 \pm 0.042$ \\
$1368-367$ & $0.059 \pm 0.062$ & $-0.035 \pm 0.083$ \\
$461-416$ & $0.087 \pm 0.031$ & $-0.112 \pm 0.043$ \\
$558-416$ & $0.205 \pm 0.003$ & $-0.010 \pm 0.004$ \\
$810-416$ & $0.253 \pm 0.018$ & $-0.062 \pm 0.025$ \\
$929-416$ & $0.057 \pm 0.056$ & $0.095 \pm 0.077$ \\
$1368-416$ & $0.043 \pm 0.024$ & $-0.035 \pm 0.032$ \\
$558-632$ & $0.238 \pm 0.014$ & $-0.049 \pm 0.019$ \\
$810-558$ & $0.446 \pm 0.031$ & $-0.008 \pm 0.042$ \\
$810-632$ & $0.150 \pm 0.029$ & $-0.033 \pm 0.039$ \\
$1368-632$ & $0.053 \pm 0.032$ & $-0.041 \pm 0.042$ \\
$810-714$ & $0.217 \pm 0.035$ & $0.003 \pm 0.047$ \\
& & \\
& &
\end{tabular}


TABLE 2

Mixing ratios deduced in the present study

\begin{tabular}{|c|c|c|}
\hline$E_{\gamma}(\mathrm{keV})$ & Sequence ${ }^{\text {) }}$ & $\delta$ \\
\hline 211 & $\frac{8}{2}(Q, O) \frac{6}{2}$ & $\begin{array}{l}0.100 \pm 0.007 \\
3.77 \pm 0.09\end{array}$ \\
\hline 264 & $(D, Q)$ & $\begin{array}{l}-2.26 \pm 0.02 \\
-0.128 \pm 0.004\end{array}$ \\
\hline 338 & $8(D, Q) \frac{7}{2}$ & $\begin{array}{c}-0.129 \pm 0.016 \\
12.0 \pm 2.0\end{array}$ \\
\hline 367 & $8(D, Q)$ & $-0.290 \pm 0.009$ \\
\hline 416 & $(\mathrm{D}, \mathrm{Q})$ & $0.087 \neq 0.019$ \\
\hline 558 & $\frac{7}{2}(D, Q)$ & $-1.1 \pm 0.4$ \\
\hline 632 & $\frac{6}{2}(\mathrm{D}, \mathrm{Q}) \frac{\mathrm{Z}}{2}$ & $\begin{array}{l}0.064 \pm 0.015 \\
-4.4 \pm 0.3\end{array}$ \\
\hline 714 & $z(D, Q) \frac{8}{2}$ & $\begin{array}{l}0.26 \pm 0.08 \\
6.0 \pm 3.0\end{array}$ \\
\hline 1193 & $\frac{8}{2}(\mathrm{D}, \mathrm{Q}) \frac{\mathrm{f}}{2}$ & $\begin{array}{l}0.90 \pm 0.06 \\
0.61 \pm 0.04\end{array}$ \\
\hline 1264 & $\frac{5}{2}(\mathrm{D}, \mathrm{Q})$ & $-0.6 \pm 0.3$ \\
\hline
\end{tabular}

The sign convention of Krane and Steffen $\left.{ }^{9}\right)$ is used for $\delta$.

2) Dipole, quadrupole and octupole radiation are denoted by $D, Q$ and $O$, respectively.

b) The value for the lifetime of the $475 \mathrm{keV}$ level makes this value for $\delta(211)$ unlikely.

$416 \mathrm{keV}$ transitions. Correlations were studied to determine $\delta(558)$ also, but statistical errors were too large to produce conclusive results.

Mixing ratios for the 367 and $416 \mathrm{keV}$ transitions were determined for all possible spin assignments for the 216,264 and $632 \mathrm{keV}$ levels with the assumption that the spin of the ground state is $\frac{3}{2}$. The value $\frac{1}{2}$ was ruled out for the spin of the 216 level because the (1242-216) and (1313-216) keV correlations were not isotropic. Requiring that $\delta(367)$ produce real values for both $\delta(264)$ and $\delta(558)$ eliminated many possibilities. Further, requiring that $\delta(416)$ produce the same real value for $\delta(558)$ as that produced by $\delta(367)$ eliminated all but one sequence of spin assignments. The criterion for consistency was agreement within two standard deviations, but the deduced spin sequence produces agreement within one standard deviation. The results are presented in fig. 1 and in table 2.

\subsection{ANALYSIS OF THE SIMPLE CORRELATIONS}

The first-second correlations were analyzed in the usual manner and incorporated the above results. Spins were eliminated whenever they produced an imaginary value for the mixing ratio of one of the $\gamma$-transitions. The spin $\frac{3}{2}$ was eliminated for the $475 \mathrm{keV}$ level because the lifetime of that level $\left(116 \mu \mathrm{s}\right.$, ref. $\left.{ }^{10}\right)$ ) precludes dipole transitions to the $\frac{3}{2}$ ground state and the $264 \mathrm{keV}$ level with spin $\frac{5}{2}$. Results are presented in fig. 1 and in table 2. Mixing ratios of transitions between levels for which more than one spin sequence is possible are not shown; $\delta(216)$ and $\delta(1242)$ cannot be deduced from the present data. 


\section{Discussion}

Previous results of directional correlation studies in ${ }^{77}$ As are presented in table 3. In general, the results of the present work agree best with those of Van der Kooi and Van den Bold ${ }^{2}$ ). Disagreement between present and previous results for the (367-264), (558-416) and (558-632) keV correlations is probably due to the much better resolution of the $\mathrm{Ge}(\mathrm{Li})$ detectors used in the present study compared to the poorer resolution of $\mathrm{NaI}(\mathrm{Tl})$ detectors, at least one of which was used in all previous investigations. The complex $\gamma$-spectrum allows for competing cascades to attenuate the correlations if the resolution of the detectors is not sufficient. Comparison of the $\mathrm{Ge}(\mathrm{Li})$ spectrum (fig. 2) in the present work with a typical $\mathrm{NaI}(\mathrm{Tl})$ spectrum [e.g. fig. 2 in ref. ${ }^{2}$ )] shows the improvement in resolution.

Spin assignments made in the present investigation agree with those currently accepted ${ }^{8}$ ). Recently, Betts et al. ${ }^{11}$ ) deduced the spin and parity of the $2000 \mathrm{keV}$ level to be $\frac{9}{2}{ }^{+!}$using data from the reaction ${ }^{76} \mathrm{Ge}\left({ }^{3} \mathrm{He}, \mathrm{d}\right)$. The present study is not in disagreement with those results.

Several different models have been proposed for odd- $Z$ nuclei in this mass region with varying degrees of success. The model of Kisslinger and Sorensen ${ }^{12}$ ) uses the

TABLE 3

Previously measured directional correlation coefficients in ${ }^{77} \mathrm{As}$

\begin{tabular}{|c|c|c|c|}
\hline Cascade $[E(\mathrm{keV})]$ & $A_{22}$ & $A_{44}$ & Refs. \\
\hline$(211-264)$ & $\begin{array}{l}-0.190 \pm 0.004 \\
-0.173 \pm 0.005 \\
-0.175 \pm 0.003\end{array}$ & $\begin{array}{l}-0.009 \pm 0.004 \\
-0.011 \pm 0.008 \\
-0.028 \pm 0.004\end{array}$ & $\begin{array}{c}\text { 1) } \\
\text { 2) } \\
\text { present work }\end{array}$ \\
\hline$(416-216)$ & $\begin{array}{r}-0.031 \pm 0.007 \\
0.003 \pm 0.015 \\
0.005 \pm 0.003\end{array}$ & $\begin{array}{r}0.017 \pm 0.009 \\
0.024 \pm 0.029 \\
-0.003 \pm 0.004\end{array}$ & $\begin{array}{c}\text { 1) } \\
\text { 2) } \\
\text { present work }\end{array}$ \\
\hline$(367-264)$ & $\begin{array}{l}-0.321 \pm 0.009 \\
-0.360 \pm 0.012 \\
-0.393 \pm 0.003\end{array}$ & $\begin{array}{l}-0.007 \pm 0.012 \\
-0.023 \pm 0.019 \\
-0.032 \pm 0.004\end{array}$ & $\begin{array}{c}\text { 1) } \\
\text { 2) } \\
\text { present work }\end{array}$ \\
\hline$(558-367)$ & $\begin{array}{l}-0.035 \pm 0.020 \\
-0.14 \pm 0.05 \\
-0.108 \pm 0.007\end{array}$ & $\begin{aligned} 0.068 & \pm 0.020 \\
-0.05 & \pm 0.07 \\
-0.019 & \pm 0.009\end{aligned}$ & $\begin{array}{c}\text { 1) } \\
\text { 2) } \\
\text { present work }\end{array}$ \\
\hline$(558-416)$ & $\begin{array}{l}0.163 \pm 0.016 \\
0.16 \pm 0.04 \\
0.123 \pm 0.006 \\
0.205 \pm 0.003\end{array}$ & $\begin{array}{c}0.052 \pm 0.024 \\
-0.01 \pm 0.05 \\
-0.003 \pm 0.010 \\
-0.010 \pm 0.004\end{array}$ & $\begin{array}{c}\text { 1) } \\
\text { 2) } \\
\text { 4) } \\
\text { present work }\end{array}$ \\
\hline$(558-632)$ & $\begin{array}{l}0.085 \pm 0.027 \\
0.13 \pm 0.05 \\
0.13 \pm 0.06 \\
0.238 \pm 0.014\end{array}$ & $\begin{array}{c}0.065 \pm 0.030 \\
-0.28 \pm 0.10 \\
0.11 \pm 0.07 \\
-0.049 \pm 0.019\end{array}$ & $\begin{array}{c}\text { 1) } \\
\text { 2) } \\
\text { 3) } \\
\text { present work }\end{array}$ \\
\hline$(810-558)$ & $\begin{array}{l}0.37 \pm 0.13 \\
0.446 \pm 0.031\end{array}$ & $\begin{array}{l}-0.03 \pm 0.16 \\
-0.008 \pm 0.042\end{array}$ & $\stackrel{2 \text { ) }}{\text { present work }}$ \\
\hline
\end{tabular}


quasiparticle random-phase approximation with pairing plus quadrupole force as a residual interaction. While this model agrees with experiment in other mass regions, it predicts a ground-state spin of $\frac{1}{2}$ and two levels with spins $\frac{5}{2}$ and $\frac{3}{2}$ near $250 \mathrm{keV}$ for ${ }^{77}$ As. Kisslinger and Kumar ${ }^{13}$ ) modified this model by assuming the entire effect of the static quadrupole is given by the anharmonicity of the doubly even system and correctly predict the $\frac{3}{2}^{-}$ground state. They also suggest $\frac{5}{2}^{-}$and $\frac{1}{2}^{-}$ levels near $150 \mathrm{keV}$.

Scholz and Malik ${ }^{14}$ ) account for the low-lying $\frac{9}{2}{ }^{+}$and $\frac{5}{2}^{+}$levels using a Coriolis coupling model with a residual interaction of the pairing type and indicate a positive deformation of the nucleus. The $\frac{3}{2}^{+}$and $\frac{5}{2}{ }^{+}$levels predicted by this model to be about $1 \mathrm{MeV}$ above the $\frac{9}{2}^{+}$level may be the 1458 and $1528 \mathrm{keV}$ levels which have these spins indicated by the present work. Betts et al. ${ }^{15}$ ) propose that the model correctly predicts the $\frac{9}{2}^{+} 2000 \mathrm{keV}$ level.

Imanishi et al. ${ }^{16}$ ) consider the motion of an unpaired quasiparticle moving in a Nilsson orbit to be coupled by a Coriolis force to the rotational motion and predict the lower odd-parity levels.

Paradellis and Hontzeas ${ }^{17}$ ) note that doubly even nuclei in this mass region do not exhibit the characteristic spectra of a deformed nucleus and object to the model of Scholz and Malik on that basis. They consider each nucleus to consist of a doubly even vibrating core and an extra-core proton quasiparticle. The interaction Hamiltonian for the quasiparticle core includes a dipole and a quadrupole term. They correctly predict the low-lying $\frac{9^{+}}{2}$ and $\frac{5}{2}{ }^{+}$levels in ${ }^{75} \mathrm{As}$ and also predict $\frac{3}{2}^{+}$and $\frac{5}{2}^{+}$levels about $1 \mathrm{MeV}$ above the $\frac{g}{2}^{+}$level. These results should also be applicable to ${ }^{77}$ As which has a similar level structure.

The authors wish to thank Dr. Peter L. Gardulski for his helpful discussions and Dr. Henry C. Griffin for his help with the chemistry.

\section{References}

1) M. B. Martin and M. L. Wiedenbeck, Nucl. Phys. 48 (1963) 65

2) J. B. van der Kooi and H. J. van den Bold, Nucl. Phys. 70 (1965) 449

3) D. D. Long, R. J. Onega and R. C. Sauer, Can. J. Phys. 49 (1971) 2082

4) R. C. Chopra and P. N. Tandon, Phys. Rev. C10 (1974) 774

5) G. Y. Chow, P. L. Gardulski and M. L. Wiedenbeck, Nucl. Instr. 116 (1974) 105

6) M. E. Rose, Phys. Rev. 91 (1953) 610

7) D. C. Camp and A. L. Van Lehn, Nucl. Instr. 76 (1969) 192; Nucl. Instr. 87 (1970) 147

8) P. P. Urone, L. L. Lee, Jr. and S. Raman, Nucl. Data Sheets 9 (1973) 229

9) K. S. Krane and R. M. Steffen, Phys. Rev. C2 (1970) 724

10) A. W. Schardt, Phys. Rev. 108 (1957) 398

11) R. R. Betts, S. Mordechai, D. J. Pullen, B. Rosner and W. Scholz, Nucl. Phys. A230 (1974) 235

12) L. S. Kisslinger and R. A. Sorensen, Rev. Mod. Phys. 35 (1963) 853

13) L. S. Kisslinger and K. Kumar, Phys. Rev. Lett. 19 (1967) 1239

14) W. Scholz and F. B. Malik, Phys. Rev. 176 (1968) 1355

15) R. R. Betts, D. J. Pullen, W. Scholz and B. Rosner, Phys. Rev. Lett. 26 (1971) 1576

16) N. Imanishi, M. Sakisaka and F. Fukuzawa, Nucl. Phys. A125 (1969) 626

17) T. Paradellis and S. Hontzeas, Can. J. Phys. 49 (1971) 1750 